Idaho National Engineering and Environmental Laboratory

INEEL/EXT-98-00966

September, 1998

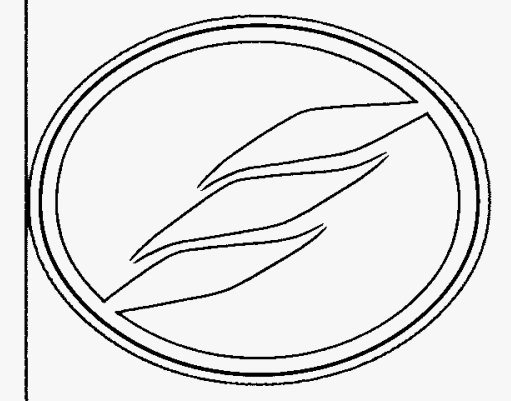

D. E. Berrett

C. J. Bargelski

L O C KHEED MARTIN 


\begin{tabular}{|l|}
\hline For additional copies or information on this document, \\
please contact \\
Chris Ischay \\
Lockheed Martin Idaho Technologies \\
P.O. Box 1625, MS 3454 \\
Idaho Falls, ID 83415 \\
Ph. (208)526-4382 \\
Fax (208)526-8878 \\
cpi@inel.gov
\end{tabular}




\section{DISCLAIMER}

Portions of this document may be illegible in electronic image products. Images are produced from the best available original document. 


\title{
CHEMICAL AND METALLURGY RESEARCH (CMR) SAMPLE TRACKING SYSTEM DESIGN DOCUMENT
}

\author{
D. E. Berrett \\ C. J. Bargelski
}

Published September 1998

Idaho National Engineering and Environmental Laboratory

Defense Program Environmental Surety. Program

Lockheed martin Idaho technologies Company

Idaho Falls, Idaho 83415

Prepared for the

U.S. Department of Energy

Office of Defense Programs

Under DOE Idaho Operations Office

Contract DE-AC07-941D13223 


\section{EXECUTIVE SUMMARY}

The purpose of this document is to describe the system architecture of the Chemical and Metallurgy Research (CMR) Sample Tracking System at Los Alamos National Laboratory.

During the course of the document observations are made concerning the objectives, constraints and limitations, technical approaches, and the technical deliverables. 


\section{TABLE OF CONTENTS}

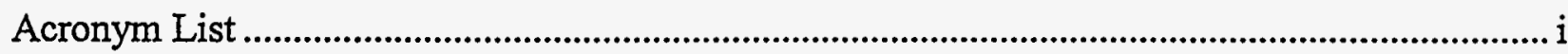

1. Introduction.

2. System Objectives............................................................................................................. 1

3. Design Constraints and Limitations..................................................................................... 1

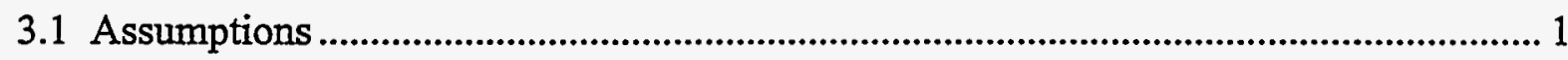

3.1.1 Web Application................................................................................................... 1

3.1.2 Inventory Application............................................................................................... 2

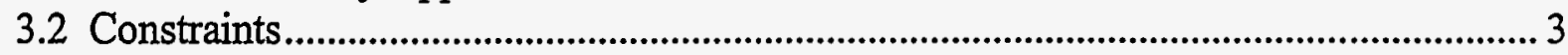

3.2.1 Web Application................................................................................................... 3

3.2.2 Conventions For Oracle Tables and Fields ....................................................... 3

3.2.3 Inventory Application.............................................................................................. 3

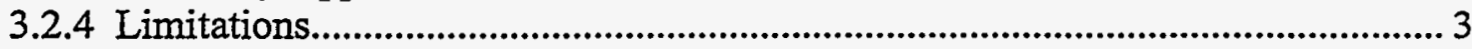

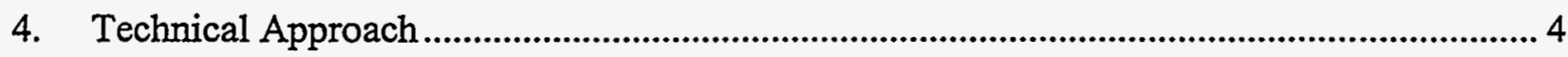

4.1 INEEL Development Environment ............................................................................ 4

5. Technical Deliverables..................................................................................................... 5 


\section{ACRONYM LIST}

CLSNM

CMR

CMRTS

DBA

INEEL

ODBC

LANL

RF

SQL*IMMS

SQL*NET
Chemical Laboratory System for Nuclear Material

Chemical and Metallurgy Research [Building]

Chemical and Metallurgy Research Tracking System

Database Administer

Idaho National Engineering and Environmental Laboratory

Open Database Connectivity

Los Alamos National Laboratory

Radio Frequency

Structured Query Language Laboratory Information Management System

Structured Query Language Network 


\section{CHEMICAL AND METALLURGY RESEARCH (CMR) SAMPLE TRACKING SYSTEM}

\section{INTRODUCTION}

This document describes the software system architecture of a sample tracking application to be implemented as an extension of the Los Alamos National Laboratory (LANL) Chemical and Metallurgy Research [Building] (CMR) Structured Query Language Laboratory Information Management System (SQL*LIMS) database. This application will operate independent of the current Chemical Laboratory System for Nuclear Material (CLSNM) application, but will update the same database tables.

The system is user-driven with a certain degree of concurrency. Thus, the system architecture is based on an interactive user interface and is partitioned by functionality. Specific functions were included or omitted in this scope as a result of iterative development, including customer feedback during the requirements process. These changes include Send-Cut, AcceptCut, and In-Transit capabilities currently available in the existing LANL SQL*LIMS application.

\section{SYSTEM OBJECTIVES}

The objective of the Chemical and Metallurgy Research Tracking System (CMRTS) is to enable CMR personnel to track the physical location of Cuts of Accountable Analytical Chemistry samples in the CMR building. The system must take advantage of labels with barcoded sample identification numbers currently printed and attached to the cuts. The system must be simple, intuitive, familiar, and easy enough to use to present an advantage over the current application's capabilities. It must also provide a level of tracking information currently not available.

\section{DESIGN CONSTRAINTS AND LIMITATIONS}

\subsection{ASSUMPTIONS}

\subsubsection{Web Application}

Due to compatibility issues with many of the ORACLE products, compatible versions of Standard Query Language Network (SQL*NET) and the Listener must be established and installed by LANL prior to the installation of the Idaho National Engineering and Environmental Laboratory (INEEL) Web Software. An NT 4.0 Server with Service Pack 3 must be in place with Internet Information Server 4.0 configured for Client access. An ODBC driver must also be installed and configured for proper connectivity.

It should be noted the connection will be through ODBC through SQL*NET to the LISTNER. This chain must be compatible and in place for the INEEL Web Software to function properly. INEEL will help to establish this compatibility and recommend what versions to install. 
In order to effectively develop and test the application against real scenarios, INEEL must have certain access privileges to the development and production environment database at LANL. Database Administrator (DBA) rights in the development environment are necessary to view the Oracle constraint tables, Select rights in the production environment are necessary to pull realistic data for testing. It is also assumed the database structures in development are duplicates of the production structures - at least for those tables accessed by this application.

LANL is expected to continue to use the VAX 6440 computer for the Oracle database and to use a DEC Alpha platform for Web applications.

\subsubsection{Software}

The following software must be installed on the DEC-Alpha

- NT Server 4.0

- Service pack 3

- Internet Information Server 4.

- ODBC, and

- SQI*NET to the Oracle database VAX production platform.

\subsubsection{Hardware}

- Connection between DEC Alpha and VAX machines is available through local Intranet, via TCP/IP.

\subsubsection{Licenses}

- LANL will provide all necessary licenses for Oracle.

- LANL will provide all necessary licenses for SQL*NET

\subsubsection{Rights}

- The development environment Oracle tables are duplicates of production tables.

- INEEL will have DBA rights in the LANL development environment.

- INEEL will have Select rights in the LANL production environment.

\subsubsection{Assumptions}

- The development environment must mirror the production environment.

\subsubsection{Inventory Application}

- Each client platform used for inventory data uploading will have an available serial port.

- Exception reports will be displayed locally on the client.

- ODBC and SQL*NET must be installed on client conducting inventory.

- Inventory will be conducted via portable readers, with no Radio Frequency (RF) capability.

- LANL will NOT provide necessary readers, communications docks and cabling to support each inventory client machine. 


\subsection{CONSTRAINTS}

\subsubsection{Web Application}

The software must run in a Browser for local Intranet use. ODBC connectivity will be through SQL*NET to an Oracle database running on the DEC VAX. Any connection to the database will be through Public Synonyms and Views, therefore those Synonyms and Views (Column Names) must remain a constant for the Software to function properly.

- Netscape 4.x or Internet Explorer 4.x only for Web clients.

- Only Intranet connectivity - no external connection to Internet.

- ORACLE7 Server Release 7.0.16.6.2.

- Oracle Listener Version 2.0.15.0.

- Oracle SQLNET version of 2.0.1.5.

- DEC VAX 6640 running VMS 6.1

\subsubsection{Conventions For Oracle Tables and Fields}

Naming conventions for Oracle tables and fields must remain constant. Specifically:

- CNAS_ = Pub. Synonym to View of like-named SQL*LIMS factory table.

- $\mathrm{CNAV}_{-}=$View of like-named SQL*LIMS factory table.

- NAI - SQL*LIMS factory table.

- $\mathrm{CLSS}_{-}=$Pub. Synonym to View of CLSNM table.

- $\mathrm{CLSV}_{-}=$View of CLSNM table.

- $\mathrm{CLS}_{-}{ }_{-}=$CLSNM Table.

- Column Names and Views

\subsubsection{Inventory Application}

The software application to run on the portable readers will be developed using $\mathrm{C} / \mathrm{C}++$. The upload and reporting application to run on the inventory client will be developed in Visual Basic. The client software will connect directly to the Oracle database via ODBS drivers. Exception and inventory reports will be generated at the local client by Visual Basic.

- Visual $\mathrm{C} / \mathrm{C}++$ version 1.52 .

- Visual Basic version 5.0.

- Readers will Symbol 4600 PPT compatible.

\subsubsection{Limitations}

It should be noted that the speed of the Web Server, Database, Local Network, or Client will affect the performance of this Web Software.

- Standard speed limitations on the Web Server, Database Server, and Client.

- The transmission speed of the local Intranet is a limitation.

- Memory size on readers will determine the number of records stored. 


\section{TECHNICAL APPROACH}

The approach is to develop the application in a duplicate environment at the INEEL, then port the application to LANL's environment. The INEEL environment will consist of a Web Server, operating with the specified versions of OS, Web, database, and client software connecting remotely to an Oracle database. The duplication applies only to the Web Server and Clients. The SQL*NET software will attach directly to the LANL VAX Oracle database rather than to a local INEEL database. This is to avoid duplication of tables and data that already exist in LANL's local application.

\subsection{INEEL DEVELOPMENT ENVIRONMENT}

The INEEL development environment will consist of:

- JavaScript, Active Server Pages 2.0, InterDev 6.0, ODBC

- Visual Basic 5.0, Visual C/C++1.52

Figure 1 depicts the planned development architecture.

Figure 1.

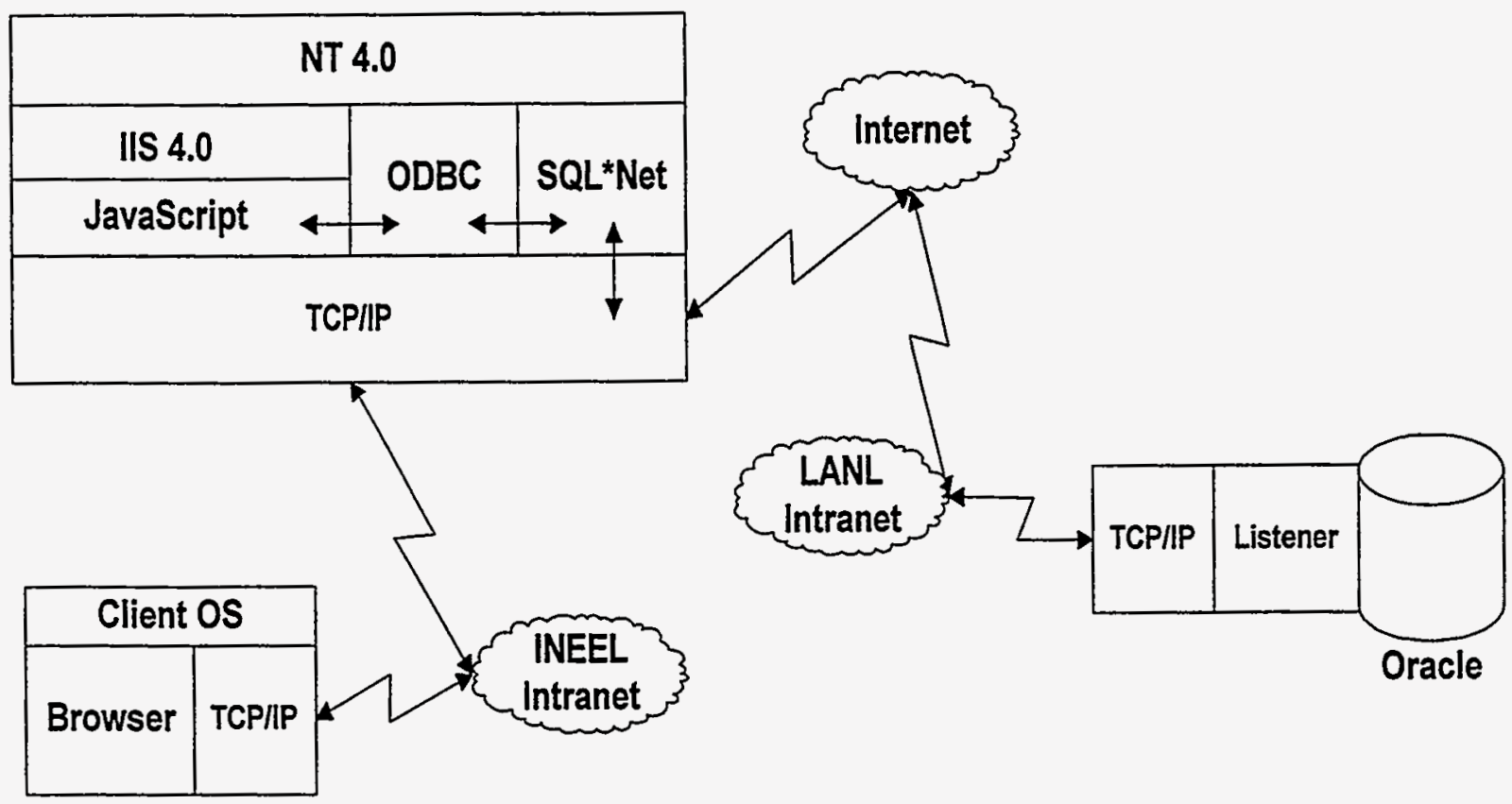




\section{TECHNICAL DELIVERABLES}

The Web application software delivered to LANL will be Active Server Pages written in JavaScript using Microsoft Visual InterDev 6.0. JavaScript running on the Server side will connect through SQLNET to the Listener running on the database Server. The JavaScript will then Query and Update the Database with ODBC.

The inventory application will be delivered as a compiled executable file ready for installation on an inventory client. The reader application will be an executable file in hex format ready for download to a portable reader. 